\title{
INFLUENCE OF INLAY PREPARATION DESIGN ON THE TRUENESS OF DIFFERENT IMPRESSION TECHNIQUES
}

\author{
Mazen Attia* and Kamal Khaled Ebeid**
}

\begin{abstract}
Statement of problem. Limited data is available on the effect of inlay preparation design on the trueness of digital impressions obtained by intra-oral scanners and conventional impressions.
\end{abstract}

Purpose. The purpose of this study was to evaluate the influence of inlay preparation design on the trueness of different impression techniques

Material and methods. Two typodont resin teeth representing maxillary first premolars were prepared for disto-occlusal inlay preparations with two different divergent angels $\left(6^{\circ}\right.$ and $\left.12^{\circ}\right)$. The prepared teeth were mounted in two typodont dental models and were used as reference models. Each reference model was scanned using an extra-oral scanner. A total of 40 digital impressions of the reference models were obtained using two different intra-oral scanners (3Shape Trios and Cerec Omnicam). For the conventional impressions, each reference model was duplicated 10 times for each preparation design $(\mathrm{n}=10)$ using a stock metal-tray and a vinyl polysiloxane impression material to obtain a total of 20 conventional impressions. Then, all impressions were scanned using the previously used extra-oral scanner. Subsequently, all impressions were poured with modified dental stone, then each cast was scanned 10 times for each preparation design $(n=10)$ using the same extra-oral scanner to obtain a total of 20 working casts. Both reference models and all (STL) files $(n=80)$ were loaded into a $3 \mathrm{D}$ reverse engineering software. For the trueness measurement, color difference maps and reports $(n=80)$ were obtained by superimposing the digital data sets of the scans from the two intra-oral scanners onto the reference model, then (3D) deviation analysis was performed with the best-fit algorithm method. By using this method, for each superimposition, the root mean square (RMS) of the amount of deviation at each measurement point was recorded.

Results. Two-way ANOVA revealed statistically significant differences between the taper, impression technique, and significant interaction. $12^{\circ}$ taper showed statistically significant higher trueness values when compared to $6^{\circ}$ taper. As for impression technique, the impression scan and the cast scan were statistically significantly better than the intra-oral scan. However, there was no statistically significant difference either between the impression scan and the cast scan or between the Omnicam and the 3Shape Trios scan.

Conclusion. Inlay preparation with 12 degrees axial wall divergence is significantly better than the 6 degrees axial wall divergence, in terms of trueness.

Clinical implications. Special care should be considered during capturing the image while using intra-oral scanners for inlay restorations.

\footnotetext{
* Lecturer, Fixed Prosthodontics Department, Faculty of Dentistry, Beni Suef University, Beni Suef, Egypt.
}

** Lecturer, Fixed Prosthodontics Department, Faculty of Dentistry, Ain Shams University, Cairo, Egypt. 


\section{INTRODUCTION}

Conventional dental impression taking for tooth preparations is still the gold standard for replicating the intraoral condition. ${ }^{(1)}$ However, inherent problems still exist with this approach, such as voids inclusion, improper tray selection, lack of co-adaptation between the impression material and the impression tray, distortion of elastic impressions, expansion of stone casts ;in addition, to time consumption and patient discomfort, especially those with gag reflex..$^{(2,3)}$

To overcome these problems, digital (virtual) models can be obtained by capturing three-dimensional (3D) images of dental preparations using computer aided design/computer aided manufacturing (CAD/CAM) technology. ${ }^{(4,5)}$ These models can be obtained by scanning a cast or an impression using an optical camera, contact probe, and laser beam,,$^{(6,7)}$ or by scanning the patient dentition directly using intra-oral scanners (IOS), expressed as computer-aided impressioning (CAI) to produce final restorations; thus, possible laboratory errors are eliminated and the time needed for the fabrication and scanning process is reduced..$^{(8-11)}$

According to many studies, digital impressions are advantageous over conventional impression taking, in terms of accuracy. ${ }^{(12,13)}$ According to the international organization for standardization (ISO), accuracy is expressed in terms of trueness and precision (ISO 5725-1). ${ }^{(14)}$ Ideally, an (IOS) should have a higher precision (a more predictable measurement when the process is consistently repeated), and a high trueness (less deviation as closely as possible from the reference object proportions). ${ }^{(10,15)}$ However, application of the sprayed powder ${ }^{(16)}$ and reflection on tooth surface caused by saliva during intraoral scanning may decrease the accuracy during digital impression taking. ${ }^{(17)}$

In order to evaluate the trueness of an IOS, a reference model of the same scanned object, obtained with industrial optical scanners with accuracy $(<5 \mu \mathrm{m})$ is obligatory; subsequently, the IOS will be superimposed on the reference model using the reverse engineering software in order to evaluate the deviations between measurements. ${ }^{(18,19)}$ Assessing clinical trueness during digital or conventional impressions is a complicated procedure because the reference model used for comparison depends on the precise capturing of the complex natural tooth structure dimensions. ${ }^{(20)}$

Several factors influence the (3D) image acquisition of the IOS, such as retraction cord placement, powder application, presence of saliva, angle of capturing, dryness of the area to be digitized, limited inter-arch space and the scanning strategy method. ${ }^{(21,22)}$

Several in-vitro studies have revealed that IOS can capture accurate impressions for the fabrication of inlays, onlays, single crowns and fixed dental prosthesis restorations. ${ }^{(23,24)}$ These results have been verified by several clinical investigations. ${ }^{25-}$ 27) On the other hand, some studies concluded that IOS showed statistically significant lower accuracy when compared to conventional impressions. ${ }^{(10,28)}$

Few studies have focused on the trueness of IOS during image acquisition, therefore; the purpose of this study was to evaluate the influence of inlay preparation design on the trueness of different impression techniques. The null hypothesis was there is no difference in the trueness value between digital impressions obtained by different IOS and conventional impressions for different inlay preparations.

\section{MATERIALS AND METHODS}

Two typodont resin teeth (Nissin Dental Product, Kyoto, Japan) representing maxillary first premolars were prepared for disto-occlusal inlay preparations with two different divergent angels according to the general principles of intra-coronal ceramic restorations. ${ }^{(29)}$ The inlay preparations have the following dimensions: $4 \mathrm{~mm}$ bucco-lingual width, $3 \mathrm{~mm}$ pulpal depth, $5 \mathrm{~mm}$ gingival depth and $6^{\circ}$ and 
$12^{\circ}$ axial wall divergence (the sum of the divergence of the 2 axial walls)(Fig.1).

The prepared teeth were mounted in two typodont dental models (Nissin Dental Product, Kyoto, Japan) and were used as reference models. Each reference model was scanned using an extra-oral scanner (Identica Hybrid) with a standardized protocol according to the manufacturer recommendations and each scan was converted into standard tessellation language (STL) data file format to create digital reference data (CAD reference model).

A total of 40 digital impressions of the reference models were obtained using two different IOS with different scanning strategies. For the 3Shape Trios IOS, each reference model was scanned 10 times for each preparation design $(n=10)$ to obtain a total of 20 digital files. The scan process began from the occlusal surface of the second molar towards the first premolar in a sweep motion followed by the lingual and buccal surfaces, respectively. The angle of scanning is 45-90 degrees to the long axis of the teeth to complete the sweep and to determine the contact points. The scanning strategy depends on light oscillation falling on the object resulting from an illumination pattern from the light source. Continuous images were recorded to form the virtual (3D) model. For the Cerec Omnicam IOS, each reference model was scanned 10 times with each preparation design $(n=10)$ to obtain a total of 20 digital files. The scan process began with placing the camera at a distance of 0-15 $\mathrm{mm}$ above the tooth surface and the same curve of exploration was performed like the previous IOS. The scanning strategy depends on stitching separate individual images together creating a yellow dental stone-like digital cast. Continuous images and video were recorded to create a virtual (3D) model. Table I. specifies the scanners used in this study.

For the conventional impressions, each reference model was duplicated 10 times for each preparation design $(n=10)$ using a stock metal- tray and a vinyl polysiloxane impression material (Express $^{\mathrm{TM}}$ STD,3M ESPE, St. Paul, USA, LOT N928424) to obtain a total of 20 conventional impressions. Then, all impressions were scanned using the previously used extra-oral scanner. Subsequently, all impressions were poured with modified dental stone (New Fujirock, GC), then each cast was scanned 10 times for each preparation design $(n=10)$ using the same extra-oral scanner to obtain a total of 20 working casts. The scanned data for conventional impressions and working casts were converted into (STL) file format to create a virtual (3D) model.

Both CAD reference models and all (STL) files $(n=80)$ were loaded into a 3D reverse engineering software (Geomagic Qualify ${ }^{\mathrm{TM}}$ 2012, Geomagic, Morrisville, USA) and all unnecessary information were cut using the "cut with planes" function. For the trueness measurement, color difference maps and reports $(\mathrm{n}=80)$ were obtained by superimposing the digital data sets of the scans from the two IOS onto the reference model, then (3D) deviation analysis was performed with the best-fit algorithm method ${ }^{(30)}$ to evaluate and visualize the positive (expansion) and negative (contraction) discrepancies (in micrometers) on a color coded image of the superimposition (Fig.2). By using this method, for each superimposition, the root mean square (RMS) of the amount of deviation at each measurement point was recorded using the equation below :(31)

$$
\mathrm{RMS}=\sqrt{\frac{\sum_{m=1}^{n}\left(x_{1, m}-x_{2, m}\right)^{2}}{n}}
$$

The data collected was checked for normal distribution and analyzed using two-way analysis of variance (ANOVA), followed by Tukey's HSD test (SPSS v20, Chicago, IL, USA) at a significance level of $\mathrm{P} \leq 0.05$. 
TABLE (I) Different scanners specifications used in this study.

\begin{tabular}{|c|c|c|c|c|c|c|c|}
\hline Scanner & Company & Software & Impression system & $\begin{array}{c}\text { Light } \\
\text { source }\end{array}$ & $\begin{array}{c}\text { Image } \\
\text { type }\end{array}$ & $\begin{array}{c}\text { In office } \\
\text { milling }\end{array}$ & $\begin{array}{c}\text { Output } \\
\text { format }\end{array}$ \\
\hline $\begin{array}{c}\text { Identica } \\
\text { Hybrid }\end{array}$ & $\begin{array}{c}\text { Medit, Seoul, } \\
\text { Korea }\end{array}$ & & $\begin{array}{c}\text { Phase shifting optical } \\
\text { triangulation }\end{array}$ & $\begin{array}{c}\text { Blue } \\
\text { LED } \\
\text { light }\end{array}$ & Image & NO & STL \\
\hline Trios & $\begin{array}{c}\text { 3 Shape, } \\
\text { Copenhagen, } \\
\text { Denmark }\end{array}$ & v4.4.0.41651 & $\begin{array}{c}\text { Ultrafast Optical } \\
\text { Sectioning and } \\
\text { conofocal microscopy }\end{array}$ & $\begin{array}{c}\text { Blue } \\
\text { LED } \\
\text { light }\end{array}$ & Video & No & $\begin{array}{c}\text { Proprietary } \\
\text { or STL }\end{array}$ \\
\hline $\begin{array}{c}\text { Cerec AC } \\
\text { Omnicam }\end{array}$ & $\begin{array}{c}\text { Sirona, Bensheim, } \\
\text { Germany }\end{array}$ & 4.4 .4 & $\begin{array}{c}\text { Active triangulation } \\
\text { (Multicolor stripe } \\
\text { protection) }\end{array}$ & $\begin{array}{c}\text { White } \\
\text { light }\end{array}$ & video & Yes & Proprietary \\
\hline
\end{tabular}

\section{RESULTS}

The mean values and standard deviations (SD) of trueness measured in micrometers $(\mu \mathrm{m})$ of all groups are listed in (Table II).

Two-way ANOVA revealed statistically significant differences between the taper, impression technique, and significant interaction (Table III). $12^{\circ}$ taper showed statistically significant higher trueness values $(0.068 \pm 0.0045 \mu \mathrm{m})$ when compared to $6^{\circ}$ taper $(0.080 \pm 0.010 \mu \mathrm{m})$. As for impression technique, the impression scan and the cast scan were statistically significantly better than the intraoral scan. However, there was no statistically significant difference either between the impression scan $(0.069 \mu \mathrm{m})$ and the cast scan $(0.070 \mu \mathrm{m})$ or between the Omnicam $(0.080 \mu \mathrm{m})$ and the 3ShapeTrios $(0.078 \mu \mathrm{m})$ scan.
In the $6^{\circ}$ axial wall divergence preparation design, the cast scan had the best performance in terms of general trueness $(0.0727 \pm 0.003 \mu \mathrm{m})$, followed by impression scan $(0.0701 \pm 0.003 \mu \mathrm{m})$, 3Shape Trios $(0.0889 \pm 0.003 \mu \mathrm{m})$ and Omnicam $(0.0921 \pm 0.003 \mu \mathrm{m})$. No statistically significant difference was found either between the impression scan and the cast scan or between the Omnicam and the 3ShapeTrios scans. However, the impression scan and the cast scan were statistically significant better than the intra-oral scan $(P<.05)$.

For the $12^{\circ}$ axial wall divergence preparation design, the cast scan $(0.0683 \pm 0.004 \mu \mathrm{m})$ had the best performance in terms of general trueness, followed by the 3Shape Trios $(0.0684 \pm 0.005 \mu \mathrm{m})$, the impression scan $(0.0684 \pm 0.004 \mu \mathrm{m})$, and Omnicam $(0.0696 \pm 0.004 \mu \mathrm{m})$. No statistically significant difference was found between any impression techniques.

TABLE (II) Mean (SD) of all subgroups in $\mu \mathrm{m}$

\begin{tabular}{|c|c|c|c|c|c|}
\hline & & \multicolumn{4}{|c|}{ Impression technique } \\
\hline & & Impression Scan & Cast Scan & Omnicam & 3shape trios \\
\hline & & Trueness & Trueness & Trueness & Trueness \\
\hline & & Mean(SD) & Mean(SD) & Mean(SD) & Mean(SD) \\
\hline \multirow{2}{*}{ Taper } & 6 degrees & \multirow{2}{*}{$\begin{array}{l}0.0701(0.003)^{\mathrm{a}} \\
0.0684(0.004)^{\mathrm{a}}\end{array}$} & \multirow{2}{*}{$\begin{array}{l}0.0727(0.003)^{\mathrm{a}} \\
0.0683(0.004)^{\mathrm{a}}\end{array}$} & \multirow{2}{*}{$\begin{array}{l}0.0921(0.003)^{\mathrm{b}} \\
0.0696(0.004)^{\mathrm{a}}\end{array}$} & \multirow{2}{*}{$\begin{array}{l}0.0889(0.003)^{b} \\
0.0684(0.005)^{2}\end{array}$} \\
\hline & 12 degrees & & & & \\
\hline
\end{tabular}

Means with different superscript letters are statistically significant. 
TABLE (III) Two-way analysis of variance (ANOVA) test of significance comparing the effect of different variables on the trueness.

\begin{tabular}{|l|c|c|c|c|c|}
\hline Source & $\begin{array}{c}\text { Type III Sum of } \\
\text { Squares }\end{array}$ & df & Mean Square & F & Sig. \\
\hline Corrected Model & $.005^{\mathrm{a}}$ & 7 & .001 & 38.384 & .000 \\
\hline Intercept & .314 & 1 & .314 & 17817.422 & .000 \\
\hline Taper & .002 & 1 & .002 & 120.097 & .000 \\
\hline Impression technique & .001 & 3 & .000 & 26.616 & .000 \\
\hline Taper* Impression technique & .001 & 3 & .000 & 22.915 & .000 \\
\hline Error & .001 & 48 & $1.760 \mathrm{E}-005$ & & \\
\hline Total & .319 & 56 & & & \\
\hline Corrected Total & .006 & 55 & & & \\
\hline
\end{tabular}

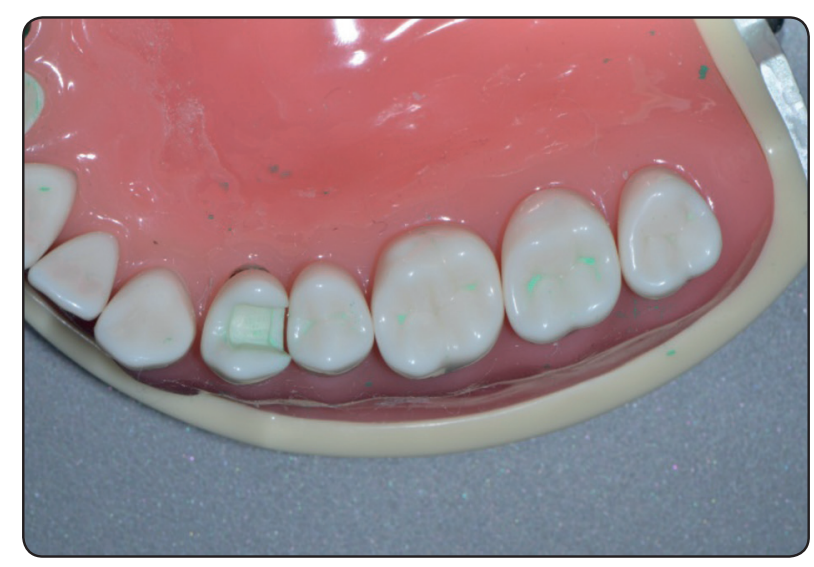

Fig. (1) The typodont model with disto-occlusal inlay preparation.

\section{DISCUSSION}

The null hypothesis tested in this study, that there is no difference in the trueness of the digital impressions taken by IOS and conventional impressions, was rejected. The results revealed that the trueness of the impression scan and the cast scan were statistically significantly better than the digital impressions obtained by IOS for inlay preparation with 6 degrees axial wall divergence; however, no significant difference was noted in the 12 degrees axial wall divergence.

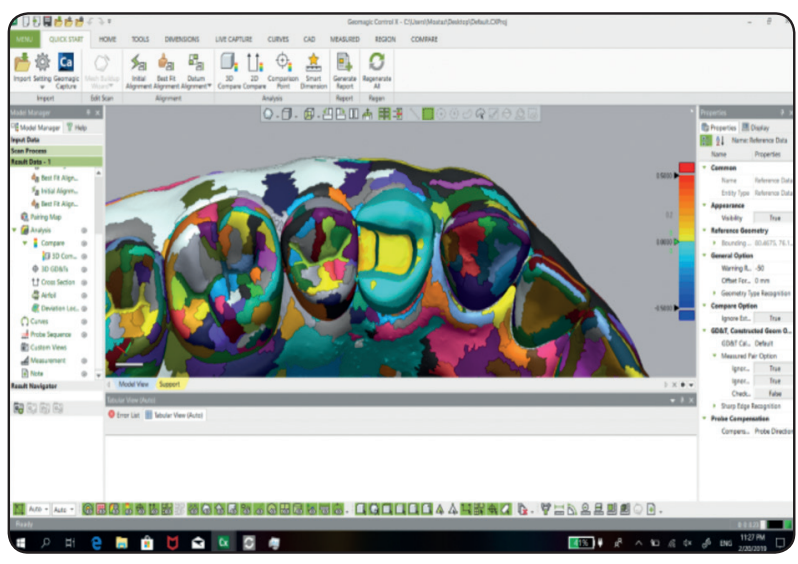

Fig. (2) Color coded image of the superimposition of the scan data on the reference data using the reverse engineering software for trueness evaluation.

In recent years, the increased clinicians demand for replacing the conventional impressions by digital impressions using IOS have been increased. In fact, virtual impressions are easier to take by the clinician and more tolerable by the patient. ${ }^{(2)}$

In this study, two typodont models were selected due to their opacity, dimensional stability, chemical resistance and good mechanical properties according to the manufacturer. The two models were prepared with different axial wall divergent angels to receive an inlay restoration and scanned with an industrial scanner to obtain a CAD reference model. Each 
preparation design with different scanning methods was scanned 10 times to obtain a total of 80 digital impressions. This was in accordance with previous studies to obtain reliable and consistent results. ${ }^{(32-35)}$

In this study, IOS was not selected as a reference scanner as unexpected errors may occur during the scanning procedures due to the high degree of freedom resulting in model bending; therefore, a desktop scanner (Identica) with trueness $(<0.04 \mu \mathrm{m})$ and exceeding that of other IOS systems was used as a reference scanner to create digital reference data as in previous in-vitro studies. ${ }^{(36-38)}$ For the conventional impressions scan, the reference model was duplicated in addition silicon impression material by single step double-mix technique. Franco et al. ${ }^{(39)}$ compared two-step versus singlestep double mix impression technique, and revealed that single- step impression technique had smaller discrepancies. For the cast scan, type IV dental stone was used to obtain casts from the impression to minimize the reflections that may result in scanning artifacts with the applied scanner. ${ }^{(11)}$ For the digital impressions, the reference models were scanned ten times with each advanced generation IOS (3Shape Trios, Omnicam).

In this study, all dataset obtained from different impression techniques were loaded into a recognized worldwide (3D) superimposition (reverse-engineering) software, where they were superimposed on the reference model, to evaluate trueness. ${ }^{(31,40)}$ The idea relies on calculating the square difference between a number of points $(x, y$, $\mathrm{z}$ axis) when two different scans were superimposed onto each other; then, the sum of these squares was divided by the number of points, and the square root of this value was considered the root mean square (RMS).This is probably a more precise value than an arithmetic mean because the difference between each data point is represented by a positive (expansion) value and a negative (contraction) value, and viewed on the color map as red and blue colors, respectively. ${ }^{(22)}$
With regard to trueness for the 6 degrees axial wall divergence, the impression scan had the best results $(0.0701 \mu \mathrm{m})$, followed by the cast scan $(0.0727 \mu \mathrm{m}), 3$ Shape Trios $(0.0889 \mu \mathrm{m})$ and Omnicam $(0.0921 \mu \mathrm{m})$. No statistically significant difference was found either between the impression and the cast scans or between the Omnicam and the 3Shape Trios scans; however, the impression scan and the cast scan were statistically significant better than the IOS $(\mathrm{P}<0.05)$.

In contrast, for the $12^{\circ}$ axial wall divergence preparation design, no significant difference was found between different impression techniques; however, the cast scan had the best results $(0.0683 \mu \mathrm{m})$, followed by the impression scan $(0.0684 \mu \mathrm{m})$, 3Shape Trios $(0.0684 \mu \mathrm{m})$, and Omnicam $(0.0696 \mu \mathrm{m})$. The $12^{\circ}$ taper design showed statistically significant higher trueness values $(0.068 \pm 0.0045)$ when compared to $6^{\circ}$ taper design $(0.080 \pm 0.010)$. This may be due to possible shadows that may occur during scanning procedures or limitation in the scan depth of the IOS due to the presence of an undercut related to the adjacent teeth that hindered the image acquisition. ${ }^{(41)}$

Several factors affect the trueness of an IOS, such as the data processing algorithm, scanning strategy, the operator's experience, the digital equipment performance, the camera position during scanning ,the number of scanned images, powder application or not and image acquisition method. ${ }^{(42)}$ The active triangulation strategy applied in the desktop scanner and Omnicam IOS is a conventional scanning strategy enabling the highest trueness if the conditions are ideal. In comparison, the confocal microscopic technology (3Shape) does not necessitate a certain distance for focusing, and therefore images can be captured regardless of whether the scanner tip is attached to the teeth when the oral cavity is scanned. In this study, trueness was evaluated by capturing the image with the same motion under 
the same conditions and the deviations in trueness increased with Omnicam with active triangulation and decreases with the 3 Shape Trios with the confocal microscopic technology. These results were in conflict with the results of a previous study on E4D dentist, CEREC, Lava COS, and iTero which found better results in the active triangulation, followed by confocal microscopy and optical coherence tomography, respectively. ${ }^{(43)}$ However, Seelbach et al. ${ }^{(44)}$ and Ender et al. ${ }^{(45)}$ studied trueness using iTero, CEREC, and Lava COS, and reported no notable difference between the parallel confocal scanners and the active triangulation scanners, while Schaefer et al. ${ }^{(46)}$ suggested that the confocal microscopy displayed higher accuracy than the active triangulation, consistent with this study. Moreover, the obtained results was in accordance with the results of Mario et al. ${ }^{(47)}$ who found that the difference of the trueness between the 3Shape Trios and Omnicam scanners could be attributed to scanning principles in addition to data processing algorithms.

In the color map of the trueness of the conventional impressions, a slight negative deviation was observed on the molar area. This could be attributed to the pressure induced during impression taking using an individual tray. In both models with different preparation designs, a slight positive deviation was observed in the cervical region. This could be attributed to the tensile stresses generated in the interproximal area of the impression during the impression withdrawal, resulting in impression deformation.

In the color map of the trueness of the digital impression data, slight negative and positive deviations were distributed on the buccal and lingual sides of the model, respectively. This was observed in spite of the model type as scanning process started from posterior molar to the right central incisor. These deviations could be attributed to the angle of capturing and the scanner head position. Another possible explanation is that the area into which the LEDs are projected during scanning procedures expands towards the major axis, resulting in possible scan errors. ${ }^{(48,49)}$ Previous studies have reported that trueness decreased as the scanning range of the digital impressions expanded. ${ }^{(50)}$

Our study has some limitations. First, it is an in vitro-study; therefore, the obtained results should be co-related to the oral condition, where the scan quality could be affected by some factors, such as blood, saliva, reflections from tooth and limited mouth opening. ${ }^{(51,52)}$ Second, the scanner used as a reference was an optical scanner; nevertheless, scanning the models using a contact probe scanner might be preferable in terms of accuracy. ${ }^{(11,18)}$ Third, this study evaluated the accuracy of IOS and conventional impressions in terms of trueness only and not to compare several commercial scanners. Thus, future investigations are needed to simulate oral conditions including the use of the latest IOS to validate the results and to provide more data to the clinicians.

\section{CONCLUSIONS}

Within the limits of the present study, the following conclusions could be drawn:

1. Inlay preparation with 12 degrees axial wall divergence is significantly better than the 6 degrees axial wall divergence, in terms of trueness.

2. Conventional impression scan and cast scan is significantly better than the intraoral scan, in terms of trueness; however, no significant difference was found either between the impression and the cast scans or between the Omnicam and the 3Shape Trios scan.

3. 3Shape Trios IOS and Omnicam IOS have comparable values of trueness. 


\section{REFERENCES}

1. Gjelvold B, Chrcanovic BR, Korduner EK, CollinBagewitz I, Kisch J. Intraoral digital impression technique compared to conventional impression technique. A randomized clinical trial. J Prosthodont 2016; 25:282-7.

2. Patzelt SBM, Lamprinos C, Stampf S, Att W. The time efficiency of intraoral scanners. An in vitro comparative study. J Am Dent Assoc 2014; 145:542-51.

3. Ender A, Mehl A. Full arch scans: conventional versus digital impressions-an in-vitro study. Int $\mathrm{J}$ Comput Dent 2011; 14:1-21.

4. Ting-Shu S, Jian S. Intraoral digital impression technique: a review. J Prosthodont 2015; 24: 313-21.

5. Albdour EA, Shaheen E, Vranckx M, Mangano FG, Politis $\mathrm{C}$, Jacobs R. A novel in vivo method to evaluate trueness of digital impressions. BMC Oral Health. 2018; 18:117.

6. Liu PR. A panorama of dental CAD/CAM restorative systems. Compend Contin Educ Dent 2005; 26:507-8, 510 , 512 passim; quiz 517, 527.

7. Güth JF, Keul C, Stimmelmayr M, Beuer F, Edelhoff D. Accuracy of digital models obtained by direct and indirect data capturing. Clin Oral Investig 2013; 17:1201-8.

8. Beuer F, Schweiger J, Edelhoff D. Digital dentistry: an overview of recent developments for $\mathrm{CAD} / \mathrm{CAM}$ generated restorations. Br Dent J 2008; 204:505-11.

9. Mangano F, Gandolfi A, Luongo G, Logozzo S. Intraoral scanners in dentistry: a review of the current literature. BMC Oral Health. 2017; 17:149.

10. Ender A, Mehl A. Accuracy of complete-arch dental impressions: a new method of measuring trueness and precision. J Prosthet Dent 2013; 109:121-8.

11. Patzelt SB, Emmanouilidi A, Stampf S, Strub JR, Att W. Accuracy of full-arch scans using intraoral scanners. Clin Oral Investig 2014; 18:1687-94.

12. Johnson GH, Mancl LA, Schwedhelm ER, Verhoef DR, Lepe X. Clinical trial investigating success rates for polyether and vinyl polysiloxane impressions made with full-arch and dual-arch plastic trays. J Prosthet Dent 2010; 103:13-22.

13. Stober T, Johnson GH, Schmitter M. Accuracy of the newly formulated vinyl siloxanether elastomeric impression material. J Prosthet Dent 2010; 103:228-39.
14. International organization for standardization. ISO-5725-

1. Accuracy (trueness and precision) of measurement methods and results. Part 1: General principles and definitions. Geneva, Switzerland: International Standards for Organization (ISO); 1994.

15. Goracci C, Franchi L, Vichi A, Ferrari M. Accuracy, reliability, and efficiency of intraoral scanners for full-arch impressions: a systematic review of the clinical evidence. Eur J Orthod 2016; 38:422-8.

16. Su TS, Sun J. Comparison of repeatability between intraoral digital scanner and extraoral digital scanner: An invitro study. J Prosthodont Res 2015; 59:236-42.

17. Flügge TV, Schlager S, Nelson K, Nahles S, Metzger MC. Precision of intraoral digital dental impressions with iTero and extraoral digitization with the iTero and a model scanner. Am J Orthod Dentofacial Orthop 2013; 144:47-8.

18. Güth JF, Edelhoff D, Schweiger J, Keul C. A new method for the evaluation of the accuracy of full-arch digital impressions in vitro. Clin Oral Investig 2016; 20:1487-94.

19. Andriessen FS, Rijkens DR, van der Meer WJ, Wismeijer DW. Applicability and accuracy of an intraoral scanner for scanning multiple implants in edentulous mandibles: a pilot study. J Prosthet Dent 2014; 111:186-94.

20. Ender A, Mehl A. Accuracy in dental medicine, a new way to measure trueness and precision. J Vis Exp 2014; 86:e51374.

21. Ender A, Zimmermann M, Attin T, Mehl A. In vivo precision of conventional and digital methods for obtaining quadrant dental impressions. Clin Oral Investig 2016; 20:1495-504.

22. Medina-Sotomayor P, Pascual MA, Camps AI. Accuracy of four digital scanners according to scanning strategy in complete-arch impressions. PLoS One. 2018; 13:e0209883.

23. Ueda K, Beuer F, Stimmelmayr M, Erdelt K, Keul C, Guth JF. Fit of 4-unit FDPs from $\mathrm{CoCr}$ and zirconia after conventional and digital impressions. Clin Oral Investig 2016; 20:283-9.

24. Abdel-Azim T, Rogers K, Elathamna E, Zandinejad A, Metz M, Morton D. Comparison of the marginal fit of lithium disilicate crowns fabricated with CAD/CAM technology by using conventional impressions and two intraoral digital scanners. J Prosthet Dent 2015; 114:554-9. 
25. Ahrberg D, Lauer HC, Ahrberg M, Weigl P. Evaluation of fit and efficiency of CAD/CAM fabricated all ceramic restorations based on direct and indirect digitalization: a double-blinded, randomized clinical trial. Clin Oral Investig 2016; 20:291-300.

26. Zarauz C, Valverde A, Martinez-Rus F, Hassan B, Pradies G. Clinical evaluation comparing the fit of all-ceramic crowns obtained from silicone and digital intraoral impressions. Clin Oral Investig 2016; 20:799-806.

27. Joda T, Bragger U. Digital vs. conventional implant prosthetic workflows: a cost/time analysis. Clin Oral Implants Res 2015; 26:1430-5.

28. Ender A, Mehl A. In-vitro evaluation of the accuracy of conventional and digital methods of obtaining full-arch dental impressions. Quintessence Int 2015; 46:9-17.

29. Shillingburg HT, Hobo S, Whitsett L, et al: Fundamentals of Fixed Prosthodontics (ed 3). Chicago, Quintessence, 1997, pp.119-137, 171-174.

30. Luthardt RG, Koch R, Rudolph H, Walter MH. Qualitative computer aided evaluation of dental impressions in vivo. Dent Mater 2006; 22:69-76.

31. Jeon JH, Hwang SS, Kim JH, Kim WC. Trueness and precision of scanning abutment impressions and stone models according to dental CAD/CAM evaluation standards. J Adv Prosthodont 2018; 10:335-9.

32. Rhee YK, Huh YH, Cho LR, Park CJ. Comparison of intraoral scanning and conventional impression techniques using 3-dimensional superimposition. J Adv Prosthodont 2015; 7:460-7.

33. González de Villaumbrosia P, Martínez-Rus F, GarcíaOrejas A, Salido MP, Pradíes G. In vitro comparison of the accuracy (trueness and precision) of six extraoral dental scanners with different scanning technologies. J Prosthet Dent 2016; 116:543-50.

34. Serag M, Nassar T Al, Avondoglio D, Weiner S. A Comparative Study of the Accuracy of Dies Made from Digital Intraoral Scanning vs. Elastic Impressions: An In Vitro Study. J Prosthodont 2018; 27:88-93.

35. Medina-Sotomayor P., Pascual A., Camps I. Relationship between resolution and accuracy of four intraoral scanners in complete-arch impressions. J Clin Exp Dent 2018; 10:e361-6.

36. Kim SR, Lee WS, Kim WC, Kim HY, Kim JH. Digitization of dental alginate impression: Three-dimensional evaluation of point cloud. Dent Mater J 2015; 34:835-40.
37. Paranhos LR, Lima CS, da Silva RH, Daruge Júnior E, Torres FC. Correlation between maxillary central incisor crown morphology and mandibular dental arch form in normal occlusion subjects. Braz Dent J 2012; 23:149-53.

38. Park HN, Lim YJ, Yi WJ, Han JS, Lee SP. A comparison of the accuracy of intraoral scanners using an intraoral environment simulator. J Adv Prosthodont 2018; 10:58-64.

39. Franco EB, da Cunha LF, Herrera FS, Benetti AR. Accuracy of Single-Step versus 2-Step Double-Mix Impression Technique. ISRN Dent 2011; 2011:341546.

40. Vecsei B, Joós-Kovács G, Borbély J, Hermann P. Comparison of the accuracy of direct and indirect three-dimensional digitizing processes for CAD/CAM systems - An in vitro study. J Prosthodont Res 2017; 61:177-84.

41. Park JM. Comparative analysis on reproducibility among 5 intraoral scanners: sectional analysis according to restoration type and preparation outline form. J Adv Prosthodont 2016; 8:354-62.

42. Hayama H, Fueki K, Wadachi J, Wakabayashi N. Trueness and precision of digital impressions obtained using an intraoral scanner with different head size in the partially edentulous mandible. J Prosthodont Res 2018; 62:347-52.

43. Nedelcu RG, Persson AS. Scanning accuracy and precision in 4 intraoral scanners: an in vitro comparison based on 3-dimensional analysis. J Prosthet Dent 2014; 112:1461-71.

44. Seelbach P, Brueckel C, Wöstmann B. Accuracy of digital and conventional impression techniques and workflow. Clin Oral Investig 2013; 17:1759-64.

45. Ender A, Mehl A. Influence of scanning strategies on the accuracy of digital intraoral scanning systems. Int J Comput Dent 2013; 16:11-21.

46. Schaefer O, Decker M, Wittstock F, Kuepper H, Guentsch A. Impact of digital impression techniques on the adaption of ceramic partial crowns in vitro. J Dent 2014; 42:677-83.

47. Imburgia M, Logozzo S, \& Hauschild U, Veronesi G, Mangano C, \& Mangano FG. Accuracy of four intraoral scanners in oral implantology: A comparative in vitro study. BMC Oral Health 2017; 17:92.

48. Lee JJ, Jeong ID, Park JY, Jeon JH, Kim JH, Kim WC. Accuracy of single-abutment digital cast obtained using intraoral and cast scanners. J Prosthet Dent 2017; 117:253-9. 
49. Jeon JH, Choi BY, Kim CM, Kim JH, Kim HY, Kim WC. Three-dimensional evaluation of the repeatability of scanned conventional impressions of prepared teeth generated with white- and blue-light scanners. J Prosthet Dent 2015; 114:549-53.

50. Su TS, Sun J. Comparison of repeatability between intraoral digital scanner and extraoral digital scanner: an in-vitro study. J Prosthodont Res 2015; 59:236-42.
51. Renne W, Ludlow M, Fryml J, Schurch Z, Mennito A, Kessler R, Lauer A. Evaluation of the accuracy of 7 digital scanners: An in vitro analysis based on 3-dimensional comparisons. J Prosthet Dent 2017; 118, 36-42.

52. Chochlidakis KM, Papaspyridakos P, Geminiani A, Chen CJ, Feng IJ, Ercoli C. Digital versus conventional impressions for fixed prosthodontics: A systematic review and meta-analysis. J Prosthet Dent 2016; 116:184-90. 